\title{
CINE Y COMPROMISO CRÍTICO EN LA SEGUNDA GENERACIÓN DEL EXILIO EN MÉXICO
}

\author{
CINEMA AND CRITICAL ENGAGEMENT IN THE SECOND \\ GENERATION OF EXILE IN MEXICO
}

\author{
Nuria de Orduña Fernández \\ Universidad Alfonso X El Sabio
}

\begin{abstract}
This paper proposes an approach to the critical and cinematographic contributions made by the writers of the second generation of the Spanish exile in Mexico. The main goal of the article is to show the concordance between the ideas that we find in their film reviews and in their literary criticisms: aesthetic concerns and reflections on the audience and the spectator, the role of the critics, cinema as creation and the figure of the author-director, the existential concern, the critical independence and the dialogism related to the institutional footprint of their background and to the theories of the cinema of the sixties. A critical and creative praxis that transformed the critical and cinematographic panorama of Mexico during the sixties and seventies. Particular attention is paid to Grupo Nuevo Cine and its magazine, as well as to the making of the film En el Balcón Vacio.
\end{abstract}

Key words: Second generation of exile in Mexico, Critique, New Cinema, Mexican literatura, Exile. 


\section{RESUMEN}

Este artículo propone una aproximación a las aportaciones críticas y cinematográficas que realizaron los escritores de la segunda generación del exilio en México. El objetivo es mostrar la concordancia entre las ideas que recorren sus críticas cinematográficas y las críticas literarias: preocupaciones estéticas y reflexiones en torno al público y el espectador, la función de la crítica, el cine como creación y la figura del autor-director, la preocupación existencial, la independencia crítica y el dialogismo que se relacionan con la huella institucionista de su formación y con las teorías del cine de los años sesenta. Una praxis crítica y creativa que transformó el panorama crítico y cinematográfico de México durante los años sesenta y setenta. Se presta especial atención al Grupo Nuevo Cine y a su revista, así como a la realización de la película En el balcón vació.

Palabras clave: Segunda generación del exilio español en México, Crítica, Nuevo Cine, Literatura mexicana, Exilio.

Fecha de recepción: 8 de noviembre de 2020 .

Fecha de aceptación: de diciembre de 2020.

Cómo citar: Orduña Fernández, Nuria de (2020): «Cine y compromiso crítico en la segunda generación del exilio en México», en Actio Nova: Revista de Teoría de la Literatura y Literatura Comparada, Monográfico 4: 446-465.

DOI: https://doi.org/10.15366/actionova2020.m4.019 
La crítica fue uno de los aspectos en los que destacaron los escritores de la segunda generación del exilio en México o escritores hispanomexicanos ${ }^{1}$. Una vocación crítica que compartían con los jóvenes escritores de la generación del medio siglo mexicano o generación de la ruptura -Enrique López Aguilar han incluido a los escritores hispanomexicanos como parte integrante de ese grupo (2012)-. Les unía la amistad y una oposición a las tendencias nacionalistas, así como un interés por las tradiciones literarias y artísticas extranjeras. Colaboraron a partir de los años 50 en proyectos que fueron fundamentales en la transformación cultural de México como las revistas México en la Cultura, Revista Universidad de México, Revista Mexicana de Literatura, La Cultura en México, Cuadernos del viento, en donde ejercieron la crítica literaria y cinematográfica, o en instituciones culturales como La casa del Lago desde donde se promovió Poesía en Voz Alta. Espacios de apertura y de modernización en donde integraron elementos de la cultura popular junto a otros de la cultura más elitista o experimental. Sus aportaciones cambiaron radicalmente la forma de hacer crítica en México.

Respecto a la crítica cinematográfica, el cambio de paradigma fue clave en la transformación que a partir de los años sesenta vivió el cine mexicano y que suponía una ruptura con el rumbo que llevaba hasta ese momento. La crisis del cine que se inició en los años cincuenta se caracterizó por la baja calidad de sus películas, por una escasa renovación técnica y un agotamiento de las películas tradicionales -rancheras, melodramas-, junto a las medidas de un gobierno proteccionista y un sindicato del cine fuerte y cerrado que impedían un espacio de creación para las nuevas tendencias que empujaban los jóvenes artistas, más en consonancia con la Nouvelle Vague francesa o con el neorrelismo italiano (Chaumel, 2012: 70-91). Para Virginia Medina Ávila, la irrupción de poetas y novelistas, el hacer de su praxis literaria en la escena cinematográfica, trajo una renovación y una mirada fresca en los tratamientos y temáticas a partir de sus aportaciones como guionistas, adaptadores o directores. (Medina Ávila: 2010). En este contexto de intensa actividad intelectual surgieron dos proyectos claves que cambiarían la forma de hacer cine en México: la revista Nuevo Cine y la realización de la película En el balcón vacio.

En enero de 1961 un grupo de cineastas y críticos emergentes configuraron el grupo Nuevo Cine. Entre sus miembros estaban Jomí García Ascot, José de la Colina, Emilio

${ }^{1}$ En este artículo me referiré a ellos como hispanomexicanos por abordar sus aportaciones dentro del campo cultural mexicano. 
Pacheco, García Márquez, Carlos Fuentes, Emilio García Riera, Rafael Corkidi, Salvador Elizondo, Carlos Monsiváis, José María Sbert, J.L. González de León, Heriberto Lafranchi, Julio Pliego y Gabriel Ramirez. En el mes de abril de ese mismo año publicaron la revista Nuevo Cine en donde dieron a conocer el manifiesto del grupo. El objetivo de la revista y del grupo era conseguir la renovación del cine mexicano, algo que veían como esencial. En el número uno de la revista aparecían como redactores los hispanomexicanos José de la Colina, J.M. García Ascot, Emilio García Riera y los mexicanos Salvador Elizondo y Carlos Monsiváis. Más tarde se les uniría también Gabriel Ramírez. El editorial del primer número recogía íntegramente el «Manifiesto del grupo Nuevo Cine». Reivindicaban la libertad de creación del cineasta, pareja a la del literato y a la del artista, la diversidad de posiciones estéticas morales y políticas, la independencia de los círculos y de la industria cinematográfica, afirmaban su apoyo al cortometraje y al cine documental y el acceso al cine internacional menos comercial y que no se exhibía, así como la defensa de los festivales:

Al constituir el Grupo Nuevo Cine, los firmantes: cineastas, aspirantes a cineastas, críticos y responsables de Cine-clubes, declaramos que nuestros objetivos son los siguientes:

1. La superación del deprimente estado del cine mexicano. Para ello, juzgamos que deberán abrirse las puertas a una nueva promoción de cineastas cada día más necesaria. Consideramos que nada justifica las trabas que se oponen a quienes (directores, argumentistas, fotógrafos, etc.) pueden demostrar su capacidad para hacer en México un nuevo cine que, indudablemente, será muy superior al que hoy se realiza. Todo plan de renovación del cine nacional que no tenga en cuenta tal problema está, necesariamente, destinado al fracaso.

2. Afirmar que el cineasta creador tiene tanto derecho como el literato, el pintor o el músico a expresarse con libertad. No lucharemos porque se realice un tipo determinado de cine, sino para que en el cine se produzca el libre juego de la creación, con la diversidad de posiciones estéticas, morales y políticas que ello implica. Por lo tanto, nos opondremos a toda censura que pretenda coartar la libertad de expresión del cine.

3. La producción y libre exhibición de un cine independiente realizado al margen de las convenciones y limitaciones impuestas por los círculos que, de hecho, monopolizan la producción de películas. De igual manera, abogaremos porque el corto metraje y el cine documental tengan el apoyo y el estímulo que merecen y puedan ser exhibidos al gran público en condiciones justas.

4. El desarrollo en México de la cultura cinematográfica a través de los siguientes renglones:

a/ Por la fundación de un instituto serio de enseñanza cinematográfica que específicamente se dedique a la formación de nuevos cineastas.

b/ Para que se dé apoyo y estímulo al movimiento de cine-clubes, tanto en el Distrito Federal como en la provincia.

c/ Por la formación de una cinemateca que cuente con los recursos necesarios y que esté a cargo de personas solventes y responsables.

d/ Por la existencia de publicaciones especializadas que orienten al público, estudiando a fondo los problemas del cine. En el cumplimiento de tal fin, los firmantes se proponen publicar en breve la revista mensual Nuevo Cine. 

mexicano.

e/ Por el estudio y la investigación de todos los aspectos del cine

f/ Porque se dé apoyo a los grupos de cine experimental.

5. La superación de la torpeza que rige el criterio colectivo de los exhibidores de películas extranjeras en México, que nos ha impedido conocer muchas obras capitales de realizadores como Chaplin, Dreyer, Ingmar Bergman, Antonioni, Mizoguchi, etc. Obras que, incluso, han dejado grandes beneficios a sus exhibidores al ser explotadas en otros países.

6. La defensa d la Reseña de Festivales por todo lo que favorece al contacto, a través de los films y de las personalidades, con lo mejor de la cinematografía mundial, y el ataque a los defectos que han impedido a las Reseñas celebradas cumplir cabalmente su cometido.

Tales objetivos se complementan y condicionan unos a otros. Para su logro, el grupo Nuevo Cine espera contar con el apoyo del público cinematográfico consciente, de la masa cada vez mayor de espectadores que ve en el cine no solo un medio de entretenimiento, sino uno de los más formidables medios de expresión de nuestro siglo.

México, Enero de 1961. (Nuevo Cine, 1, abril, 1961)

Una carta de intenciones que no solo se quedaba en la crítica a la situación que vivía la industria cinematográfica, sino que proponía líneas claras de actuación. La periodicidad de la revista fue mensual pero pasó rápidamente a ser bimestral y terminó publicando tan solo siete números, el último en agosto de 1962. El editorial de ese número dejaba claro las dificultades económicas a las que tenía que enfrentarse la revista para seguir manteniendo su independencia crítica y solicitaba para ello el apoyo por suscripción de sus lectores:

Una revista de cine debería vivir de anuncios de cine, pero en nuestro medio esto significaría rebajarse al nivel de los carlillos y cinemundiales y, por supuesto, "vender" la crítica. Nuestros productores y distribuidores carecen, por lo visto, de la amplitud de criterio de sus colegas europeos, que incluyen anuncios de sus films en revistas como Cabiers du Cinéma y Cinéma 62 sin pedir a cambio críticas favorables. (Nuevo Cine, Número 7, agosto de 1962)

Las dificultades económica no fueron un problema exclusivo de Nuevo Cine, sino que eran un problema habitual en todas aquellas revistas que luchaban por mantener su independencia de las instituciones y de los grupos editoriales, el precio que se tenían que pagar por la libertad de expresión ${ }^{2}$.

Durante los años 60 la crítica en general se convirtió en un espacio de reivindicación y de compromiso, en algunos casos incluso de posicionamiento político, desde donde intervenir y entender la realidad. Para Tomás Segovia la función de la crítica era principalmente la de ejercer de mediadora, es decir, ordenar los discursos y las tensiones que

\footnotetext{
2 Para un estudio sobre las revistas en América Latina véase: Saul Snowosky (1999).
} 
se dirimían en el campo literario y así ayudar a establecer la comunicación entre los lectores, los escritores y los críticos. En uno de sus ensayos hacía alusión a este papel mediador:

Una literatura sin crítica presenta el curiosos aspecto de un discurso de tartamudos dirigidos a tartamudos. La ausencia de esta mediación, lejos de favorecer el contacto, es un verdadero muro de silenciación y de embrollamiento de mensajes, a un lado y otro del cual los poetas flotan sin poder ordenarse y comunicarse entre sí por la falta de argamasa lectora, y le público lo mismo por falta de argamasa espiritual y cultural (Segovia: 1988:167)

La relación que mantuvo Tomás Segovia con el cine es menor en comparación con su obra literaria y crítica poética. No obstante, participó en algunos de los proyectos más representativos que llevo a cabo la segunda generación en México: actúo en el film En el balcón vacio representando a un soldado encarcelado de las Brigadas Internacionales. Además, trabajó de secretario, de mecanógrafo y traductor de guiones mientras Max Aub era Secretario de la Comisión de Cinematografía en México. Entre sus traducciones estarían algunos guiones de cine-El acorazado Pontemkin, Hotel du Nord-, una breve incursión en el cine mexicano como actor - Tajimara, basada en un cuento de García Ponce- y sus colaboraciones en algunos de los guiones del director mexicano Manuel Barbachano Ponce (Segovia, 2012: 134). Pero, Tomás Segovia Nunca escribió para Nuevo Cine, aunque siempre mantuvo una relación de amistad y de colaboración con los miembros del grupo. José María García Ascot, José de la Colina y Tomás Segovia habían colaborado en Revista Mexicana de Literatura en sus inicios en 1955 y después continuaron cuando este último ejerció la dirección entre 1959 y enero de 1962. Una vinculación que se retrotrae a su época en los círculos y colegios del exilio -a través de la figura de Emilio Prados- y más tarde en los años de universidad. Respecto a su relación con los escritores mexicanos, cabe decir lo mismo de Salvador Elizondo y de Juan García Ponce (Segovia, 2012: 127-146). No obstante, aunque no escribió crítica cinematográfica, sí se dedicó plenamente a la crítica literaria y se pueden observar, en algunas de sus reflexiones en torno a la función del arte, coincidencias con ciertas propuestas de Nuevo Cine.

El grupo y la revista Nuevo Cine inauguraban, por lo tanto, una forma renovada de hacer crítica cinematográfica, inexistente hasta ese momento ${ }^{3}$-. Se inspiraban en las ideas de Cabiers du Cinéma y en la Nouvelle V ague, desde donde se defendían la libertad de expresión y

\footnotetext{
${ }^{3}$ Octavio Paz y Tomás Segovia denunciaban por esos años también la falta de una crítica especializada en México y reclamaban la necesidad de crear revistas literarias y culturales desde donde ejercer esta práctica. Véase Paz (2008).
} 
la libertad técnica y creativa, además de proclamar la "teoría del autor” y de creación. Emilio García Riera reconocía esa influencia:

tiende a conciliar mis propios gustos, 'inconfesables' con los valores de la cultura cinematográfica, y que me 'da permiso' de disfrutar a gusto Cantando en la llwivia, por ejemplo, porque es una película de la que cabe hablar seriamente y muy bien (...); de ahí que la influencia de Cabiers du Cinéma llegara a todo el mundo y provocara una gran revulsión en la cultura cinematográfica, ya demasiada entonces con su buena conciencia (...)... la enseñanza que yo deduje de su ejemplo fue capital: si el cine ha sido tu placer de siempre, sele fiel a ese placer, y no te dejes enajenar por la cultura de la buena conciencia estética, social y política, aunque esa cultura se proclame a sí misma enemiga de la enajenación. (Rodríguez, 2012: 102)

Por lo tanto, ¿cómo entendían que debía ser la función del cine? Para empezar, el cine debía ser una obra artística y nunca un negocio. Así, revindicaban el acceso del público a un cine experimental y no su participación exclusivamente del cine que se hacía en los circuitos comerciales que potenciaban la industria americana y la mexicana. No se oponían radicalmente a ese tipo de cine, solo reclamaban un espacio, el acceso a las mismas condiciones de producción y así ir formando un público capaz de apreciar la obra. Salvador Elizondo, en su artículo "Cine experimental” publicado en el número 3 de Nuevo Cine exponía precisamente estas cuestiones. Abogaba por un cine que fuera capaz de competir a nivel internacional dentro de las normas de producción experimental bajo los conceptos de: "festival", "cinema d'art", "cine club", “sophisticated". Tomaba el ejemplo del cine experimental que se realizaba en Estados Unidos, Italia y Francia y señalaba cómo en Francia la barrera entre cine experimental y comercial se había vuelto difusa. Salvador Elizondo traía a modo de ejemplo varias películas experimentales mexicanas de bajo presupuesto pero con capacidad para competir, por lo que el espacio existía, eso sí, todas ellas vinculadas en cierta forma al grupo Nuevo Cine: el documental Carnaval Chamula de José Baéz Esponda, El nacimiento de un volcán de Figueroa o Perfecto Luna que dirigió Archibaldo Burns en 1959 basado en un relato de Elena Garro. Aprovechaba la ocasión para mencionar varias iniciativas que el grupo Nuevo Cine estaban realizando: él mismo junto a Baéz preparaban una pequeña película «poética» sobre diversos aspectos funerarios de México, además describe el proyecto En el balcón vacio. Sobre esta película comenta:

Hace ya algunos meses que los miembros del Grupo Nuevo Cine venimos oyendo hablar de una película en vías de producción y a la que sus autores se refieren jocosamente con el título Pamplona, mon amour. Semana a semana nos iban contando incidentes de la filmación sin que acertáramos a formarnos una idea precisa. Ahora, al fin, sabemos la verdad; se trata de En el balcón vacio (título provisional), película que está siendo filmada en $16 \mathrm{~mm}$ bajo la dirección de J.M. 
García Ascot. Se trata aquí, posiblemente, de aplicar los principios de producción formulados inicialmente por Cassavetes en Shadows: film de argumento, de largo metraje, $16 \mathrm{~mm}$, escenarios naturales, realizado con vistas a su ulterior explotación comercial después de haber sido sometida al blow-up, etc (...). Creemos que de todas las actividades que han surgido en el seno del gripo Nuevo Cine, es la filmación de esta película la más ambiciosa. (1961: 9)

De esta forma, los postulados de Nuevo Cine no se quedaban solo en la teoría, sino que se ponían en práctica, tal y como lo había hecho la nowvelle vague. Para concluir, Elizondo señalaba otro de los problemas con los que se encontraban: la distribución y exhibición de las películas experimentales. La exhibición solo se podría hacer a través de la Federación Mexicana de Cineclubs, aunque esta era una propuesta que estaba todavía en desarrollo (Elizondo, 1961: 9).

Desde pronto estos escritores vieron en los cineclubs el lugar donde encontrarse y compartir su interés por el cine. Muestra de este interés fue su participación en los cineclubs que iban proliferando como espacios alternativos a las salas comerciales. Jomí García Ascot, por ejemplo, dirigió el cineclub del Instituto Francés para América Latina (IFAL) desde 1949.

Decía José de la Colina sobre la función que desempeñaban estos lugares:

El socio de un cineclub es algo más que un espectador enterado. Su labor consiste en gustar y divulgar el buen cine. Cuantos más miembros de un cineclub haya en las salas comerciales, más necesidad de buenas películas se hará sentir. Por eso resultan tontos los ataques dirigidos a los cineclubs llamándolos capillitas de snobs. ¿Se es snob por negarse a ver un culebrón lacrimoso de Libertad Lamarque, campeona del cine de mayorías? ¿No es más noble desertar de un cine estúpido y vulgar y acudir a un cine que tiene por lo menos el valor de sus intentos? Si es cierto que los cineclubs representan -ahora- minorías, también lo es que un solo fruto podrido echa a perder a todos los demás. Y lo que debe hacer el miembro de un cineclub es echar a perder al público de los grandes salones de exhibición, retirarle de sus películas desinfectadas de inteligencia, contagiarle la enfermedad de las buenas películas. ¿No sería ideal que los cineclubs se extendieran a tal grado que los productores juzgaran comercial hacer buenas películas para ellos? O mejor aún, ¿no sería ideal que los cineclubs se hicieran tan fuertes que pudieran financiar películas experimentales? (Revista Mexicana de Literatura, 1957, 12: 70)

La crítica literaria y cinematográfica reflexionó en torno a los debates sobre el esteticismo y sobre la función del arte y del cine. Coincidían en la necesidad de transformar la sociedad y para ello era imprescindible analizar la relación que se establecía con el público y con el lector. Este periodo de transformación y de modernidad económica que se estaba experimentando en América Latina trajo consigo la aparición de un nuevo público y con ellos la necesaria reflexión sobre el papel de una nueva crítica capaz de conectar y de responder a las preguntas sobre su función y su comunicación poética. La emergencia de un 
nuevo público obligaba a renovar los paradigmas de la poesía y del arte cinematográfico. Si en la literatura, en la poesía, el debate era si el autor debía adaptar su escritura a un público capaz de entenderle, si debía dirigirse a una inmensa mayoría y comulgar con una poesía más conversacional y menos hermética, una poesía de compromiso y de transformación social, o bien si debía rendir cuentas a la forma y al placer estético, aunque el resultado fuera más abstracto y solo llegara a una minoría versada. Son los años de la revolución y del compromiso del arte con la sociedad, pero las formas de entender ese compromiso eran bien distintas. Tomás Segovia defendía que el público debía acceder al misterio poético, pero sin que la poesía perdiera su carácter y misterio, por el contrario el lector debía subir al plano de la poesía. Solo así la poesía ejercía su verdadera función social y se conseguía la transformación de la sociedad y no al contrario:

La técnica ideal de un arte que aspirase a comunicarse de nuevo con su público debería ser lo más clara y asimilable que fuera posible. Pero cuanto más rica sea la técnica que logremos hacer asimilable, mayor será la riqueza que de ella habremos comunicado al lector o espectador. Lo mismo puede decirse del "fondo" (por llamarlo de algún modo y suponiendo que pueda aislarse). La función del arte es hacer asimilables unas riquezas que hasta cierto momento no lo eran y que no podrían serlo de ninguna otra manera; es comunicar lo incomunicable logrando un equivalente "fable" de lo "inefable". Es bastante dudoso que el arte realice su esencia expresando caóticamente lo caótico, o por el contrario hablando llanamente de lo que es ya efectivamente llano; pero lo que es indudable es que, incluso si realizase así su esencia, no cumpliría su función. $\mathrm{El}$ arte tiene una función y esta función puede encararse bajo un aspecto social. Pero no es verdad que resida en sus temas, sus preocupaciones, su posición histórica, ni tampoco en el lenguaje que adopta o las formas externas que toma, aunque dependa de todas estas cosas. Esta función reside en su existencia misma (...). (1973: 126)

Esta misma preocupación recorría el campo cinematográfico: la necesidad de formar un público que fuera capaz de apreciar el cine de arte. En este sentido, coincidían con Tomás Segovia, la participación del espectador y del lector se conseguían formando al público. Estos planteamientos hicieron que fueran tachados injustamente de elitistas por entenderse que escribían una obra experimental o hermética que impedía el acceso a una inmensa mayoría y un alejamiento del público. No obstante, una lectura atenta permite percibir más que elitismo la huella de una educación institucionista en ellos: la defensa del dialogismo o, si se prefiere, por el elemento dialéctico. Tomás Segovia reconocía que en algunas circunstancias este alejamiento podía producirse, pero si eso ocurría respondía a una necesidad mayor, la de buscar la autenticidad, pero autenticidad que se produce solo en el reconocimiento del otro: 
Porque para el escritor el problema del público se plantea siempre como un problema moral. Su responsabilidad primera es para la autenticidad, ya sea que la llame verdad objetiva, o ley estética, o sentimiento, o incluso religión, historia o filosofía. Esta responsabilidad tiene en él tanta prioridad, que pasa incluso antes que la consideración de las necesidades manifiestas del público. Pero por poco que se la analice, deja ver que la autenticidad se funda siempre en la coexistencia, es decir en el reconocimiento, dando a esta palabra su sentido más profundo, de la existencia de los otros, reconocimiento que es la verdadera estructura de todo público posible. Así, el escritor, y el artista, en general, sólo se aleja de las necesidades manifiestas del público para responder a las que le parecen, aun a riesgo de equivocarse, necesidades profundas, y si no "pensara" en el lector, no tendría ningún motivo para sentirse o no auténtico. (1991: 172-173)

José María García Ascot y José de la Colina fueron autores más politizados, como demuestra su vinculación con el M-59 (Aub, 1992; Aurelio, 2015). Ambos viajaron y vivieron en La Habana durante los años centrales de la Revolución y colaboraron con revistas literarias cubanas. Cercanos a los postulados del «cine realidad» cubano, creían en un cine y en una crítica que formara a un público capaz de apreciar las obras y las propuestas más experimentales. Defendían un cine alejado del cine de entretenimiento y de la industria, sin embargo, esto no quiere decir que no les interesara tampoco el cine americano, los musicales o el western. Las críticas cinematográficas de José de la Colina en las revistas cubanas muestran una atención diversa y plural tanto al cine europeo, japonés, como al americano o al de ciencia ficción (Rodríguez, 2013). La postura de Nuevo Cine era por la diversidad y no por el criterio único y alienante:

La diversidad de opiniones es su misma razón de ser como revista y se funda en la convicción de que no existe un criterio absoluto sobre lo que es buen cine, y de que no hay verdadera crítica sin dialéctica. Una revista con un director que "repartiera algunos latigazos y evitara la anarquía de opiniones" no sería una revista, sino un folleto propagandístico. (...) Nuevo Cine no cree, en efecto, que las buenas intenciones hagan el buen cine, ni que la película "favorable a la causa de la paz" o "inteligentemente antimacartista" sea por ello buena en el sentido artístico. (Ascot, 1962: 2)

Para José de la Colina el cine debía mostrar el interés por lo humano, debía alejarse de las vanguardias, del arte puro, de los artificios y de los juegos técnicos y estéticos. La finalidad del cine era trasmitir, conectar con el espectador y que este compartiera "algo". En este sentido, coincidía con Tomás Segovia en esa oposición a las vanguardias y el interés por el elemento humanista en el arte. José de la Colina ya en 1957 proponía el método dialéctico como instrumento crítico y pensaba que no consistía en rechazar aquellas películas que fueran opuestas a nuestra ideología: «Además, la dialéctica es el mejor de los métodos en toda empresa cultural» (Revista Mexicana de Literatura, 1957, 12: 70). 
En un artículo publicado en el número 3 de Nuevo Cine Jomí García Ascot reflexionaba sobre la función del cine y su relación con la realidad, es decir, planteaba el problema del realismo en el cine, qué debía mostrar:

La misión del cine -como la de todo arte- es que, después de haber estado en contacto con la obra, el espectador tenga la noción de que no todo está tan bien en este mundo como se quiere aparentar, de que, en definitiva, no estamos en el mejor de los mundos posibles (1961, 3, agosto: 10)

Para Ascot la obra artística debía "revelar al espectador que no todo es como parece" (1961: 10). Debía así mostrar los grandes temas existenciales del ser humano y de la realidad (el dolor, la muerte, el amor, la angustia existencial, los problemas sociales...). El cine no podía prescindir de ellos porque produciría una sensación de irrealidad, una desconexión, pero tampoco introducirlos como meros "puntos de referencia" de la realidad. Ascot defendía un verdadero realismo que presentase los "problemas" y preocupaciones de la vida, el cine no podía ser evasión ni huida, debía ser anticonformista.

Así progresivamente el cine nos va encerrando en un mundo cada vez más estrecho, cada vez más uniforme, cada vez más limitado. La eliminación constante de toda expresión de fisura, de grieta, de inconformidad, ha hecho de la pantalla el retrato -falso y monótonamente repetido- de un mundo "hecho" (y no por hacer), de un mundo "feliz", de un mundo "correcto". Es decir de un mundo inexistente. He aquí, a mi entender, lo que debe ser la verdadera reivindicación del realismo: reintegrar a este mundo falsificado todos aquellos elementos que le han sido sustraídos, expresar sobre la pantalla todo aquello que es pero que no se nos enseña, todo aquello que -embrutecidos-, acabaremos por olvidar bajo el constante martilleo del mensaje conformista. (1961:11)

Buñuel, Pabst, Murnau, Bergman, Rossellini, Dreyer, Resnais, Welles, Von Stroheim, Eisenstein, Pudovkin, Germaine Dulac, Cavalcanti, Chaplin, Franju, Keaton eran algunos de los cineastas inconformistas que reclamaba en esa operación de abrir los ojos a la que debían sumarse los jóvenes y nuevos cineastas.

Además de escribir críticas cinematográficas para revistas, estos escritores comenzaron a publicar ensayos y monografías especializadas que fueron publicando en editoriales tan emblemáticas como la Editorial Era, fundada por exiliados, o la editorial institucional del Fondo de Cultura Económica con las que colaboraban estrechamente. José de la Colina realizó junto a Tomás Pérez Turrent una serie de entrevistas a Luis Buñuel entre 1974 y 1975 y que se publicaron en el libro Probibido asomarse al interior (1986) en la editorial mexicana Joaquín Mortiz ${ }^{4}$ El grupo Nuevo Cine mantenía una estrecha relación en esos años

\footnotetext{
${ }^{4}$ Se publicó también bajo el título de Buñuel por Buñuel.
} 
con el director exiliado Luis Buñuel. El número 4 de la revista se dedicó íntegramente a un especial sobre Luis Buñuel, una forma de recuperar su obra y figura. En ese número colaboraron autores como Octavio Paz, Álvaro Mutis, Alberto Gironella, Henry Miller o José Bergamín y el crítico Francisco Pina, entre otros muchos.

Emilio García Riera se convirtió en un destacado historiador del cine mexicano, con obras tan monumentales como Historia documental del cine mexicano (1969) o la Historia del cine mexicano (1986), además de monografías como la de Julio Bracho (1986) o Las películas de Tin Tan (2008). Conviene mencionar un libro más personal como es El cine es mejor que la vida (1990), un recorrido en el que el autor imbrica la vida y el cine a modo de memorias. En el breve ensayo El cine y su público (1974) presenta la evolución del cine desde sus inicios hasta el momento de la escritura del ensayo y permite observar no solo la evolución y las transformaciones técnicas de la industria, que obligaron a modificar la concepción del arte, sino varias ideas en torno a su concepto de autor-creador y de la función del cine como medio de expresión creadora, además de analizar la relación que se establecía entre los tipos de espectadores y la adaptación al nuevo medio como elemento de transformación o injerencia en la realidad, a través de la mirada del autor, en donde el espectador debía activar su sentido crítico:

Nuestro punto de vista en el cine sólo puede atenerse a "otra" realidad: la propuesta por "otro" punto de vista, y deducir del encuentro de ambas los fundamentos dialécticos de una toma de posición crítica, la puesta en crisis de una idea de la realidad, la nuestra, que sólo podrá enriquecerse en el choque con otra idea de la realidad. El cine hace comparable (iy en qué forma!) que no hay una realidad dada (si existiera, lo único que debería hacerse sería fotografiarla con la mayor fidelidad posible); que lo que llamamos realidad objetiva no es sino el resultado de unas interacciones tanto más ricas cuanto más críticas, esto es, menos complacientes con lo "ya sabido". Aun las aparentes confirmaciones de puntos de vista afines al nuestro no tendrán valor crítico si no nos obligan a volver sobre nuestros pasos para saber de nuevo lo sabido, o sea, para elevar lo sabido al nuevo nivel de comprensión que la comunicación con el "otro" hace posible. Y el cuestionamiento de lo "ya sabido", la necesidad de una suerte de renovación de la inocencia, es uno de los atributos más valiosos del artista, y por ende, del autor de cine. Gracias al autor, el cine dejó de ser -en parte, claro, pero la parte más significativa e importante- el vehículo de unos poderes enajenantes para convertirse en el vehículo del otro, aquel con quien nuestros sentimientos y pensamientos entran en colisión dialéctica, en el conflictivo proceso de reconocimiento que define la toma de conciencia del mundo. (1974: 27).

Para García Riera la idea del autor de cine encontró oposición tanto en un cine capitalista e ideológico de los moralistas americanos, como desde el realismo socialista porque ambos radicalismos eliminaban las posibilidades de un cine crítico. Por eso, solo en 
la dialéctica de los contrarios se podía producir esa conciencia del mundo y en donde el autor daba sentido o valor expresivo a la realidad desde su punto de vista, desde su estilo. García Riera analizaba para ello los postulados y las películas más representativas de Griffith, Eisenstein o Vertov y señalaba las influencias que se producían a partir de un proceso dialéctico. En este ensayo analizaba también el papel del cine como medio de comunicación de masas.

Manuel Durán destacó principalmente como poeta -obras como Puente (1946), Ciutat i fugures (1952), Ciudad asediada (1954), La paloma azul (1959, El lugar del hombre (1965), La piedra en la mano (1970), Cámara oscura (1972), El lago de los signos (1978), Poemas telegráficos I y II (1977, 1978), El tres es siempre mágico (1981), Breu diari d'estiu (2001)- y como crítico literario. Los estudios en torno a su obra son más bien escasos y se han centrado más en su crítica literaria ${ }^{5}$. Destacan sus trabajos sobre literatura mexicana y sobre la literatura española: la obra de Rulfo, Fuentes, Paz, Elizondo o los clásicos españoles. Publicó en numerosas revistas mexicanas y españolas: México en la Cultura, Cuadernos Americanos, La Cultura en México, Revista Universidad de México, Insula, Revista Mexicana de Literatura, Cuadernos Hispanomexicanos, Papeles de San Armadans, Diálogos, Plural, Vuelta, entre otras. Aunque tampoco participó en Nuevo Cine siempre declaró un interés por el séptimo arte. Son pocos los textos de crítica cinematográfica que pueden encontrarse de Manuel Durán, en ese sentido destaca Vida y muerte de un mito (1965). Un breve ensayo prácticamente desconocido y publicado en 1965 en la colección de «Cuadernos de cine» de la Dirección General de Difusión Cultural de la Universidad Autónoma de México que dirigía por entonces Jaime García Terrés. Un ensayo en torno a la figura de Marilyn Monroe fallecida en 1962. En este ensayo Manuel Durán coloca a la mujer como centro de su reflexión y ese es precisamente uno de los aciertos del libro ${ }^{6}$. El autor hispanomexicano explica la construcción del concepto de mito, a partir de las ideas sobre el amor de Denis de Rougemont, para entender la devoción social por los actores y actrices elevados a su vez a figuras míticas. De esta forma analiza la invención por parte de la industria de Hollywood de las distintas tipologías de mujeres según las épocas del cine, cómo se crearon las ideas de «estrellas», el mito erótico a partir de los ideales de belleza y de la utilización de esa imagen y de la moda por parte de la industria del cine como reclamo

\footnotetext{
${ }^{5}$ Véase Noguer Ferrer, Marta; Carlos Guzmán Moncada (2005).

${ }^{6}$ Este libro en torno a la figura de Marilyn Monroe se completa con ensayos de Ernesto Cardenal «Oración por Marylin Monroe»; Norman Rosten «¿Quién mató a Norma Jean?»; Rochard Meryman «Ultima impresión de una mujer solitaria»; Clifford Odets «A quién corresponda: Marylin Monroe»; Caryl Brahms «Marylin»; Richard Meryman «Fama ¿te vas? Adiós. Ya te conozco»; Clare Booth Luce «Lo que en verdad mató a Marylin» (1965).
} 
comercial. Manuel Durán, describe cuatro tipologías de mujeres en el cine del siglo XX: desde la mujer vampiro y devoradora, que William Fox impuso en 1914 en la figura de Theda Bara, tomada a su vez de los modelos daneses y de la «vamp» italiana; la «flapper», una mujer con un aspecto más deportivo y directa que causo furor en los frenéticos años 20, pero que durante la década siguiente fue sustituida por una mujer más exótica, que representaron las bellezas sofisticadas de Greta Garbo, Marlene Dietrich o Katherine Hepburn, con un estilo más elegante y discreto, sin embargo los años cuarenta correspondieron a la llegada del tipo femenino de la «pin-up», con la que se ofrecía un amor idealista, una belleza estereotipada a través de la imagen de una mujer sonriente y simple, que encarnaron Jane Rusell, Rita Hayworth, Betty Grable y la propia Marilyn Monroe. Manuel Durán llega así hasta el mito de Marylin Monroe y plantea las tres facetas sobre las que se construyó la existencia del personaje: el mito, la artista y la mujer:

Por ello, en el conjunto real, vivo, que fue Marylin Monroe en su paso por el presente, por la historia, vamos a tratar de distinguir varias partes. Es un recurso, un subterfugio, quizá un instrumento de comprensión. Vamos a distinguir y a dividir. Por una parte, el mito -los mitos- que encarnaron en ella. Por otra, su carrera como artista: su obra en el cine. $\mathrm{Y}$, finalmente, como síntesis de las otras dos divisiones, trataremos de definirla como persona, como mujer. (1965: 45- 46)

La finalidad de su análisis es explicar el conflicto del ser humano, una preocupación por el elemento existencial, que es clave en toda su obra y que explica la existencia trágica de la actriz.

Pero si desde la faceta como escritores entendían la crítica y la praxis poética como creación, los críticos cinematográficos entendían también el cine como creación. En ese sentido, los postulados de Nuevo Cine se materializaron en la realización en 1962 de la película En el balcón vacio. Este proyecto constituye un documento fundamental de exilio y de la segunda generación al ser la única filmación que existe sobre el tema del exilio español y realizada por exiliados, características tan singulares que serían ya suficientes para subrayar su relevancia. Por el contrario, su conocimiento y difusión siguen siendo mínimos y se limitan a ciertos ámbitos académicos vinculados al exilio. La Asociación para el estudio de los Exilios y Migraciones Ibéricos Contemporáneos (AEMIC) digitalizó en el año 2009 la película y la presentó en el año 2012 junto al documental Y yo entonces me llevé un tapón. Memoria compartida. En el balcón vacio, acompañado de un libro con diversos textos y de una serie de entrevistas a algunos de los protagonistas de la película, como a Tomás Segovia o a José de la Colina (Lluch-Prats, 2012). Gracias a este proyecto ha sido posible acceder a su visionado y a esta 
parte de la memoria de nuestro exilio. Además, conviene subrayar que estamos ante un documento heterónimo, que pone de relevancia el encuentro entre el mundo del exilio y México.

La idea de la película surgió a partir del relato Tiempo de llorar de María Luisa Elío, mujer en aquel momento de José María García Ascot y escritora exiliada de la segunda generación. La dirigió José María García Ascot ${ }^{8}$ y colaboró en el guión Emilio García Riera. Se filmó durante cuarenta domingos, entre 1961 y 1962, en 16 mm y en varios escenarios de la Ciudad de México, como el Parque de Lira, El Colegio de México o el Ateneo Republicano Español. Con muy bajo presupuesto, en ella participaron varios amigos, escritores y miembros de la generación del medio siglo: Salvador Elizondo, Tomás Segovia, José de la Colina, Juan García Ponce, entre otros muchos (Fernández Martínez: 7). La película narrada desde la perspectiva de una niña, se estructura en dos partes: primero, la experiencia y el recuerdo de la guerra y del exilio de España, después ya de adulta muestra la experiencia del retorno al lugar de origen, el reencuentro, o mejor, su imposibilidad, con un espacio que no se corresponde ya con el de su recuerdo. El análisis sobre la memoria y la identidad del exilio recorre toda la historia y nos presenta la imposibilidad de ese retorno de los exiliados. Así lo entiende José María Naharro Calderón, para quien la película es una película sobre la nostalgia y sobre la memoria, lo que le confiere una proyección más universal y no exclusivamente sobre la guerra y el exilio español, aunque estos estén presentes (Naharro Calderón: 134-163). Aspecto este que coincide con el análisis de José de la Colina. El crítico hispanomexicano con motivo del estreno en 1962 escribió en el número 7 de la revista Nuevo Cine unas palabras muy parecidas en las que resaltaba, oponiéndose a la idea de Salvador Elizondo sobre la idea del contexto, que no era una película sobre la Guerra civil ni sobre el exilio, sino sobre la nostalgia y la memoria: «La montaña misma del film, su tejido de imágenes es la nostalgia» y continuaba diciendo: «una nostalgia que halla prolongación en la mía» (1962: 20). Destacaba así precisamente ese alejamiento de la obra de las vanguardias y del concepto de cine puro, de arte por el arte, que le resultaban vacíos, por el contrario la obra de García Ascot le parecía que terminaba recogiendo la nostalgia del hombre, a través de un elemento fundamental el narrativo, se acercaba así a la vida, «un cuento con imágenes, una obra intensa y llena de contenido». Defendía en el film la idea del autor y su intervención:

\footnotetext{
${ }^{7}$ Para un estudio sobre la película y los relatos de María Luisa Elío véase Eduardo Mateo Gambarte (2009). ${ }^{8}$ José María García Ascot dirigió también en México en 1967 un cortometraje sobre la pintura surrealista y exiliada en México Remedios Varo (1913-1963).
} 
«porque pretendemos que el cineasta de-debe dar- su visión del mundo, de la realidad, en la obra de arte» (1962: 21).

Sin embargo, aunque pueda parecer un proyecto amateur, y así se ha señalado en algunas ocasiones, Juan Rodríguez propone revisar esta idea y subraya la importancia de su propuesta estética (Rodríguez, 2012: 94). La película participó en varios festivales internacionales representando a México y ganó varios premios: en el Festival Internacional de Locarno en 1962 el Premio de la Crítica y en Italia en el Festival de Cine Latinoamericano de Sestri-Levante en 1963, el «Giano de Oro». Por otra parte, la recepción de la crítica fue excepcional en diversos medios mexicanos e internacionales: Elena Poniatowska, para el periódico Novedades, 22 julio de 1962; Gene Moskowitz, para Variety, Nueva York de 8 de agosto de 1962; Osvaldo Benzi, Libera Stampa, Lugano; Juan García Ponce, Revista Universidad de México, junio de 1962, entre otras muchas (Mateo Gambarte, 2012: 207-223). La mayoría de ellas señalaban el inicio de una nueva etapa para el cine mexicano, su tono poético y prosutiano, la presencia de la nostalgia y del miedo, su espíritu humano y su capacidad por narrar con tanto acierto y un tema tan delicado como era la experiencia de la guerra y del exilio, en resumidas cuentas, una obra de arte. El crítico Francisco Pina escribía en La cultura en México:

En el balcón vacío es un film de inquietudes y bellezas indudables, situado en la línea del mejor cine que se hace hoy en el mundo. No es, por lo tanto, nada rara que haya triunfado en un festival donde se aprecian y comprenden las obras en que alienta un verdadero espíritu creador y esa peculiar visión del mundo que confieren a un cineasta la calidad de autor cinematográfico.

La guerra de España, o mejor dicho, su tremenda repercusión en el frágil espíritu de una niña excesivamente sensitiva, inspiró a María Luisa Elío un bello argumento cinematográfico con doble carga emotiva y sentimental. Era preciso tratar un tema así con mucho cuidado, con ese pudor providencial que salva la caída en un sentimentalismo facilón e impropio de un artista que se estime. Con mucha inteligencia y mucho amor, García Ascot logra trasmutar en cine de radical esencia poética las obsesiones de esa niña y de la mujer en que se convertirá más tarde. (Mateo Gambarte, 2012: 210-211).

Por su parte, para Elena Poniatowska:

Esta película denuncia que las guerras -aun terminadas-, se llevan adentro y siguen destruyendo, siguen cayendo bardas y edificios interiores; sigue habiendo muerte. Esta película es el yo acuso de una niña a España (...) Con El balcón vacío, María Luisa Elío y García Ascot inician, en cierto modo, una etapa distinta del cine mexicano. Han abierto la brecha para que los integrantes del grupo Nuevo Cine: Salvador Elizondo, Emilio García Riera, José Luis González de León, José de la Colina, etcétera, actúen definitivamente en el campo cinematográfico mexicano. (Mateo Gambarte, 2012: 214) 
Todos estos escritores coincidían en unos postulados estéticos y de compromiso que defendieron en torno a la función y a la finalidad que debía tener el cine y el arte. Debía ser dialógico y creativo, desvelar la realidad a partir de la mirada personal del autor, desde una actitud liberal humanista de pensamiento libre y crítico, capaz de transformar la realidad y al espectador. Propuestas que se inspiraban en parte en las nuevas tendencias de cine experimental que venían de Francia y en las teorías del cine de Sergéi Einsestein, Dziga Vertov, Bertolt Bretch, Theodor Adorno, Max Horkheimer (Medina Ávila, 2010: 9).

Un cambio de paradigma que se dejó sentir en las publicaciones posteriores como $35 \mathrm{~mm}$ (1976-1979) o Cine (1978-1980), por citar solo algunas (Miguel, 2010:57-58), al recoger los postulados planteados por Nuevo Cine y sobre todo su compromiso crítico y riguroso. Además, la aparición de festivales independientes y experimentales como los de 1965 y 1967 y la publicación de libros y ensayos, en la Editorial Era, en el FCE o desde Difusión Cultural de la UNAM ayudaron a configurar las bases de un nuevo público en México. 


\section{BIBLIOGRAFÍA}

Aub, Elena (1992): Palabras del exilio 5: historia del ME /59. Una última ilusión, México, INAH/Conaculta, 1992.

Chaumel Fernández, Jorge (2012): «Aproximación al cine mexicano. El nacimiento de Nuevo Cine», en Lluch-Prats, Javier (ed.): En el balcón vació. La segunda generación del exilio republicano en México: Madrid, AEMIC: 70-91.

De la Colina, José (1957): en Revistas Mexicana de Literatura, 12, julio-agosto: 68-70.

De la Colina, José (1962): «En el balcón vacío», Nuevo Cine, 7, agosto: 20-22.

Elizondo, Salvador (1961): «El cine experimental», Nuevo Cine, 3, agosto: 4-9.

García Ascot, José María (1961): «Sobre el anticonformismo y el conformismo en el cine», Nuevo Cine, 3, agosto: 10-14.

García Riera, Emilio (1975): El cine y su público, México, FCE.

García Riera, Emilio (1967): El cine es mejor que la vida, México, Cal y Arena.

López Aguilar, Enrique: (2012): Los poetas hispanomexicanos. Estudio y antología, México, UAM, Ediciones Eón.

Mateo Gambarte, Eduardo (2009): María Luisa Elío Bernal. La vida como nostalgia y exilio, Logroño, Universidad de La Rioja.

Mateo Gambarte, Eduardo (2012): «En el balcón vacio: Guiones, realización y recepción», en LluchPrats, Javier (ed.): En el balcón vacio. La segunda generación del exilio republicano en México: Madrid, AEMIC: 164-225.

Medina Ávila, Virginia (2010): «Influencia de los escritores en la renovación y búsqueda del cine mexicano de los sesenta y setenta», Multidisciplina, 5: 5-21.

Miguel, Ángel (2010): «Nuevo cine», en Elizondo, Lydia (coord.): Revistas culturales latinoamericanas 1960-2008: Morelos, Universidad Autónoma del Estado de Morelos, Juan pablos Editor: 43-55.

Naharro Calderón, (2012): «Entre la Mneme de en El balcón vacio y la anamnesis de Tiempo de lloran», en Lluch-Prats, Javier (ed.): En el balcón vacio. La segunda generación del exilio republicano en México: Madrid, AEMIC: 134-163.

Noguer Ferrer, Marta; Carlos Guzmán Moncada (2005): «La obra crítica de Manuel Durán», Escritos, Revista del Centro de Ciencias del Lenguaje, 32, julio-diciembre: 109-130.

Rodríguez, Juan (2007): «Recursos para el estudio de la literatura y el cine en el exilio», Migraciones y Exilios, 8: 163-174. 
Rodríguez, Juan (2012): «En el balcón vacio y el Nuevo cine», en Lluch-Prats, Javier (ed.): En el balcón vacio. La segunda generación del exilio republicano en México: Madrid, AEMIC: 93163.

Rodríguez, Juan (2013): «José de la Colina en Cuba», en González de Garay, María Teresa; Díaz-Cuesta Galián, José (coord..): El exilio literario de 1939, 70 años después: Barcelona, Universitat Autònoma de Barcelona: 327-396.

Paz, Octavio (2008): Cartas a Tomás Segovia (1957-1985), México, FCE.

Segovia, Tomás (1973): «El poeta y el público», en Contracorrientes, México, Universidad Nacional Autónoma de México.

Segovia, Tomás (1988): Ensayos. Actitudes. Contracorrientes, México, Universidad Nacional Autónoma de México.

Segovia, Tomás (2011): «El grupo Nuevo Cine y la película En el balcón vacio: Testimonio de Tomás Segovia», Migraciones y Exilios, 12: 127-146.

Sosnowsky, Saúl (1999): La cultura de un siglo. América Latina en sus revistas, Buenos Aires: Alianza Editorial.

Velázquez Hernández, Aurelio (2015): «El movimiento español 1959: Entre la Revolución cubana y los servicios secretos mexicanos», Latinoamérica 61, 2: 130-155. 


\section{SOBRE LA AUTORA}

\section{Nuria de Orduña Fernández}

Nuria de Orduña Fernández es doctora por el departamento de Teoría de la Literatura y Literatura Comparada de la Universidad Autónoma de Madrid. Actualmente es profesorainvestigadora en la Universidad Alfonso X El Sabio en Madrid. Sus investigaciones se han centrado en la Segunda generación del exilio español y su relación con el campo cultural mexicano y con la literatura española, con especial atención a la obra poética y ensayística de Tomás Segovia. Ha participado como ponente en congresos internacionales en España, México y Francia y ha sido investigadora visitante en El Colegio de México.

Contact information: correo electrónico: ndeorfer@uax.es 